\title{
Evaluation of Visual Evoked Potentials in Patient with Angelmans Syndrome - Case Report
}

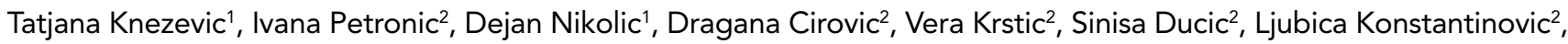
Calogero Foti $^{3}$

${ }^{1}$ Physical Medicine and Rehabilitation, University Childrens Hospital, Belgrade, Serbia

${ }^{2}$ University of Belgrade, Faculty of Medicine, Belgrade, Serbia

${ }^{3}$ Physical and Rehabilitation Medicine, Tor Vergata University, Rome, Italy

\begin{abstract}
Background: Angelman syndrome (AS) is a genetic disorder with varying degrees of neurological impairment. It is often associated with ocular involvement.

Case Report: We present a child diagnosed with AS who had a deletion on the short arm of chromosome 15. The child seemed to be happy, with developmental delay, speech problem, and altering strabismus. To assess the potential presence and degree of damage in the visual pathway, we recorded monocular flash visual evoked potentials (VEPs). Our results revealed the presence of severe central afferent dysfunction in both optical pathways.

Conclusion: VEPs can be used in patients with AS and visual disturbances to assess the integrity of the visual system.
\end{abstract}

Key Words: visual evoked potentials, angelman syndrome, children

Received: 30.10 .2012

Accepted: 08.01.2013

\section{Introduction}

Angelman syndrome (AS) is defined as a neurodevelopmental disorder (1). It is a genetic condition influenced by a deficiency in UBE3A imprinted gene expression from the maternal chromosome 15 (2). There are data in the literature implying that around $6 \%$ of children with mental retardation or epilepsy are diagnosed with AS (3). The main clinical manifestations of AS may not be present in the early life of the newborn. However, later in the life of individuals with AS, the presence of happy behaviour, impaired verbalisation, ataxic gait, hypermotoric action, facial dysmorphism, and attention problems are frequent signs and symptoms $(4,5)$. Ocular involvement, with the presence of hypopigmentation, limited to the choroid and iris stroma, has been described in AS patients (6).

\section{Case Report}

We present the case report of the child that was diagnosed with AS. It is the first child from the second pregnancy; the first one was finished ended in miscarriage. Shortly after delivery, the infant started crying even though it was cyanotic, due to the green fetal water. From anamnesis, the child achieved head control in the third month of life while the induction of seating balance and control was prolonged and established around the seventh month of life. On clinical examination when the child turned 2 years of age, it was not completely verticalised and had not established proper independent stand-on balance. The patient had problems in verbalising words. Objectively, the child seemed happy, with non-provoked and spontaneous happy behaviour. Blood tests were performed in order to assess the presence of potential genetic defects. It was discovered that there was a deletion on the short arm of chromosome 15 (15q 11-13). Following genetic testing, in-depth anamnesis, physical examination, and neurophysiological diagnosis were performed in order to assess and analyse potential clinical signs and symptoms. It was found that there was a retardation in psychomotor development for the current age; the child had not developed proper verbal pronunciation of words. On clinical examination, the child was hyperactive, with a lot of motoric actions of the upper and lower extremities. Clinically, the arms were predominantly laterally elevated. It was noticed, from heteroanamnesis, that the child had no problems with sleeping and did not experience epileptic attacks. Further, the patient had some degree of heat intolerance and moderate hypersalivation. It was noticed that the distance between the eyes was slightly reduced than the expected range. In addition, the child had altering strabismus, widely positioned lips, and diverted, anteriorly positioned teeth. Babinski and postural reflexes were tested in clinical examination. It was found that Babinski was negative, while the parachute postural reflex was positive, even though it was expected to have disappeared at the time of the examination, since the child was 2 years old. In order to assess the potential presence and degree of visual system impairment (from eyes to the visual part of the cortex), we performed a neurophysiological investigation, 


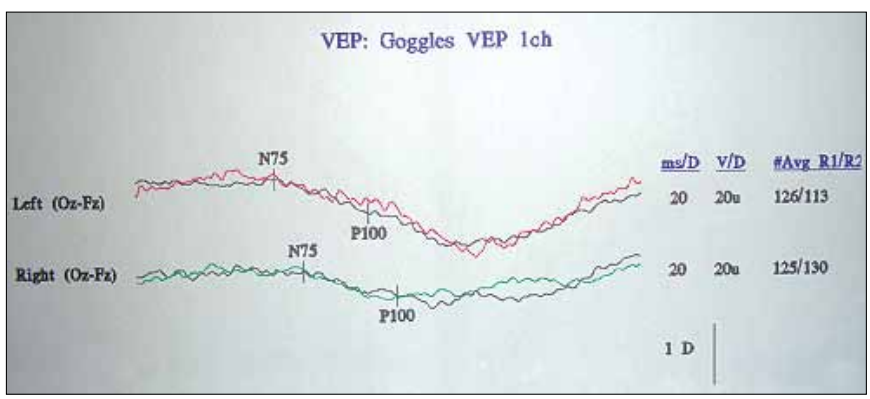

Figure 1. Visual evoked potentials charts for the left and right eyes

particularly monocular flash visual evoked potentials (VEP flash). By recording monocular flash VEPs, we showed on the right eye poorly formed and hardly marked cortical responses with low amplitudes and latencies that were within the physiological range (closer to upper physiological values), while on the left eye we observed poorly formed and non-prolonged latencies (Figures 1 and 2).

\section{Discussion}

VEPs are a neurophysiological diagnostic tool that examines the integrity of the visual pathway (7). They consist of a series of negative and positive waves that are generated with every flash. In evaluating flash VEP charts, we analyse two separate components that include the $\mathrm{N}$ (negative) peak and the $P$ (positive) peak (8). The waves in the evoked potentials that are formed during stimulation have latencies and amplitudes, which are used for quantitative evaluation (9). The latencies and amplitudes describe the integrity of the somatosensory cortex of the brain with eventual presence of certain changes within. They can give insight into central nervous system maturation and detect the presence of eventual pathological changes. It is important to stress that, particularly in children, there is a great potential for brain plasticity, with increased synaptogenesis and maturation. Therefore, the VEP diagnostics could have great benefit for the evaluation of the functional status of the central nervous system. Further, as a diagnostic tool, VEP flash stimulation can be used for the follow-up of pathological progression in the visual pathways. In our case report, monocular flash VEPs revealed the presence of severe central afferent dysfunction in both optical pathways. In the right optical pathway, during the flash stimulation, poorly synchronised cortical responses were generated. These findings suggest that the changes in the VEPs in our patient may, to the certain degree, be the result of a reduced synaptogenesis potential that might be associated with AS $(10,11)$.

During the VEP flash stimulation recording, the child was exacerbated and therefore, artifacts in both waves were observed. It is important to stress that these artifacts do not influence the latency and amplitude values.

Given the facts above, in patients with AS who present with visual disturbances, VEPs to monocular flash stimulation could provide insights into the integrity of the visual system. This technique may be especially useful in very young or uncooperative patients.

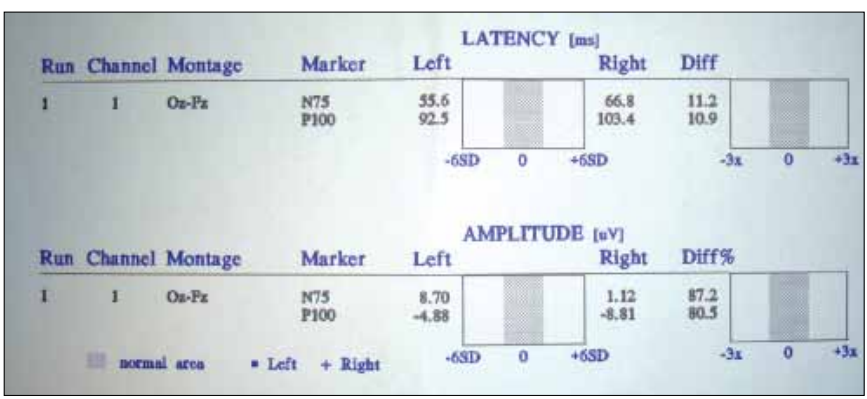

Figure 2. Latency and amplitude parameters for visual evoked potentials

Ethics Committee Approval: The evaluation was done according to the principles of good clinical practice, since this evaluation is referred as mandatory from Ophthalmologist.

Informed Consent: Written informed consent was obtained from the parent of the patient who participated in this study.

Peer-review: Externally peer-reviewed.

Author contributions: Concept - T.K., I.P., D.N.; Design - T.K., D.N., D.C.; Supervision - I.P., V.K., S.D.; Resource - T.K., V.K., L.K.; Materials - T.K., I.P., D.N.; Data Collection\&/or Processing - T.K., I.P., D.C.; Analysis\&/or Interpretation - T.K., I.P., D.N.; Literature Search - D.N., S.D., C.F; Writing - T.K., D.N., I.P.; Critical Reviews - C.F., I.P., L.K.

Conflict of Interest: No conflict of interest was declared by the authors.

Financial Disclosure: No financial disclosure was declared by the authors.

\section{References}

1. Clayton-Smith J, Laan L. Angelman syndrome:a review of the clinical and genetic aspects. J Med Genet 2003;40:87-95. [CrossRef]

2. Camprubí C, Guitart M, Gabau E, Coll MD, Villatoro S, Oltra S, et al. Novel UBE3A mutations causing Angelman syndrome:different parental origin for single nucleotide changes and multiple nucleotide deletions or insertions. Am J Med Genet A 2009;149A:343-8. [CrossRef]

3. Guerrini R, Carrozzo R, Rinaldi R, Bonanni P. Angelman syndrome:etiology, clinical features, diagnosis, and management of symptoms. Paediatr Drugs 2003;5:647-61. [CrossRef]

4. Williams CA. Neurological aspects of the Angelman syndrome. Brain Dev 2005;27:88-94. [CrossRef]

5. García Ramírez M, Csanyi B, Martínez Antón J, Delgado Marqués M, Bauzano Poley E. Genetic and clinical diagnosis of Angelman syndrome. Case Reviews. An Pediatr (Barc) 2008;69:232-8. [CrossRef]

6. Dickinson AJ, Fielder AR, Young ID, Duckett DP. Ocular findings in Angelman's (happy puppet) syndrome. Ophthalmic Paediatr Genet 1990;11:1-6. [CrossRef]

7. Pompe MT, Kranjc BS, Brecelj J. Visual evoked potentials to red-green stimulation in schoolchildren. Vis Neurosci 2006;23:447-51. [CrossRef]

8. Odom JV, Bach M, Barber C, Brigell M, Marmor MF, Tormene AP, et al. Visual evoked potentials standard (2004). Doc Ophthalmol 2004;108:115-23. [CrossRef]

9. Titlic M, Kolic K, Fiorentini F, Josipovic-Jelic Z. Predictive value of assessment of disc-radicular conflict of the cervical segment by somatosensory evoked potentials. Bratisl Lek Listy 2009;110:312-5.

10. Scheiffele $P, B$ eg AA. Neuroscience:Angelman syndrome connections. Nature 2010;468:907-8. [CrossRef]

11. Greer PL, Hanayama R, Bloodgood BL, Mardinly AR, Lipton DM, Flavell SW, et al. The Angelman Syndrome protein Ube3A regulates synapse development by ubiquitinating arc. Cell 2010;140:704-16. [CrossRef] 